\title{
Content Validity of Agility Test in Karate Kumite Category
}

\author{
Dewangga Yudhistira, Tomoliyus*
}

Faculty of Sport Sciences, Yogyakarta State University, Indonesia

Received July 31, 2020; Revised September 12, 2020; Accepted September 29, 2020

\section{Cite This Paper in the following Citation Styles}

(a): [1] Dewangga Yudhistira, Tomoliyus , "Content Validity of Agility Test in Karate Kumite Category," International Journal of Human Movement and Sports Sciences, Vol. 8, No. 5, pp. 211 - 216, 2020. DOI: 10.13189/saj.2020.080508.

(b): Dewangga Yudhistira, Tomoliyus (2020). Content Validity of Agility Test in Karate Kumite Category. International Journal of Human Movement and Sports Sciences, 8(5), 211 - 216. DOI: 10.13189/saj.2020.080508.

Copyright $\subseteq 2020$ by authors, all rights reserved. Authors agree that this article remains permanently open access under the terms of the Creative Commons Attribution License 4.0 International License

\begin{abstract}
Background: Kumite is a category in karate match. It is a one-on-one match that requires complex physical aspects, one of which is physical agility. In a real match, kumite requires movements to shift the direction quickly when a karateka aims to hit his opponent. For that reason, there should be a program and an assessment to improve the physical agility of the karate athletes who compete in kumite category. The document analysis of this research found that there has not been any assessment tool for the agility aspect in kumite, while the existing agility test measuring tool was only designed for sports in general. Purpose: This research aimed to develop the construction of karate agility test for the kumite category. Design/methodology/approach: This is a developmental research which consisted of 3 stages. In the first stage, documents and research journals were analyzed to develop the construction of karate agility test for the kumite category. In the second stage, the Delphi technique was utilized and the experts were asked to assess he construction of karate agility test for the kumite category resulted in the first stage. In the third stage, the results of expert judgment with the Aiken formula were analyzed to test the content validity. The participants in this research were documents and seven experts. Results: It was found in the construction of the Kumite category karate agility test; item one, the content or material got a $\mathrm{V}$ value of 0.85 ; item two, the distance between the cone had a $\mathrm{V}$ value of 0.95 ; item three, the safety of the equipment used has a $\mathrm{V}$ value of 0.90 ; item four, the number of test replications had a $\mathrm{V}$ value of 0.90 ; item five, the clarity of the test procedure had a $\mathrm{V}$ value of 0.90 ; items six, the clarity of the test score had a V value of 0.90 . Conclusion: The karate agility test
\end{abstract}

construction for the kumite category had high content validity.

Keywords Content Validity, Agility Test, Karate, Kumite

\section{Introduction}

Agility is a biomotor component of physical condition which is essential for several sports. Agility has been defined as a person's ability to move, stop, then start the movement again quickly, or as a rapid whole body movement with a rapid change of direction in response to a stimulus . In the field of physical training, agility is the ability of a person to move from one place to another with the aim of changing body positions . Agility can be defined as the movement of the whole body in a fast activity with changes in speed or a person's ability to change direction at high speed accurately without losing balance. In other words, agility is someone's ability to move quickly and change direction from side to side and backward. Agility is the key to success in high performance. With good agility, an athlete can move quickly. It can help an athlete to win a match or competition. Agility is a skill possessed by an athlete which is performed continuously to unexpected stimuli such as opponent movements, decision making and the ability to react to change places quickly and precisely. A karate coach should modify agility training in different ways to improve the athlete's agility . In karate, agility is indispensable for fast movements in performing techniques 
and tactics perfectly in various directions by maintaining balance of speed and body coordination...Karate is one of the most popular martial arts regularly practiced all over the world that involves defense and attack techniques with the aims of getting points from opponents .

Karate is a Japanese martial art originated from fight training which was then modified into a martial art and sport in 1921 . Karate has three elements that should be studied, namely kihon, kata and kumite. Kihon consists of basic movements that should be studied and perfected. Kihon training must be done properly and correctly. If it is not studied properly, the kohai (karate disciple) cannot proceed to the next steps. Kihon consists of hand position, push, punch, kick, good posture, jumping technique. The more often kihon is practiced with repetition of the same technique in a few years, the sharper the athlete's movement and control . Meanwhile, the kata is a predetermined movement consisting of a part of the fight without an opponent, or a series of moves from kihon which are combined into interesting moves. Kumite is a karate sparring/fight that applies the attack and defensive techniques which have been studied in kata technique. In its practice, the kumite has an aggressive nature which aims to get points from opponents during a match .

Kumite has two kinds of training, with and without opponent. If someone practices kumite systematically, it will create good moving structures, improve technique and physical agility to prepare for the real karate match . Martial art, especially the kumite category in karate, is a physical contact sport. Therefore, the physical aspect is essential to improve the athletes' achievement, because the good physical condition of the athlete will lead to the athlete's better and more effective movement and techniques, both for defense and offense. Karate, especially kumite, has the characteristics of sudden movements and explosive attacks. Therefore, a good physical aspect is essential to support these sudden and fast movements. One of the most important physical aspects is agility. Agility is a must-have-thing for kumite athletes because in a kumite match, the athletes should face moving opponents. Agility is required to perform fast, technical, and tactical movements perfectly by maintaining speed and coordination. However, there is a drawback in learning agility because the previous studies did not focus on developing agility tests specifically . In particular, field-based tests only measure general agility and do not focus on the sport that somebody specifically engaged in . Some of those field-based tests are the 505 agility test, $\mathrm{T}$ agility test, Illinois agility test, and $10 \times 5$ meter agility test . Moreover, individual sports such as martial arts or one-on-one ball games have a typical type of competition; therefore, the test must resemble the real match. There has not been any karate agility test for kumite category that resembled the techniques and movement patterns in a real kumite match. This fact is in line with some literatures stating that there has not been any agility test relating to the agility intervention conducted in the form of a match, especially for individual sport athletes. The previous research in taekwondo already designed an agility test. However, that test was only specialized for taekwondo elite athletes and obviously could not be used to measure the agility aspect in karate, especially in kumite category. So far, the karate agility test for the kumite category has not yet been found. Content validity is a measure where the content is an instrument that can be in the form of a construction or can be described as a measuring tool for measuring sport activities. The construction of the measuring tool has to be precisely built by taking into account its relevance, completeness, goals and objectives to design . Therefore, the validity test has been recognized that the validity of the instrument or a test instrument can be recognized so that it can be used properly to measure the karate agility in the kumite category. The design of a test in performance sports must be customized to each specific sport. Even though there are two categories in karate (kata and kumite), the movement patterns of both categories are very different. Due to the lack of research focusing on the karate agility test, especially in its kumite class, this research aimed to develop a measuring tool for the karate agility test in the kumite category and determine its content validity. It is expected that this research can be useful to measure the karate agility test in the kumite category.

\section{Materials and Methods}

This research used a development method by combining qualitative and quantitative approaches. This was a mixed research that combined two approaches, namely qualitative and quantitative in order to obtain more comprehensive and valid data . The mixed method is when an expert or researcher used a combination of qualitative and quantitative research methods with a single concept, or when a research is carried out sequentially or simultaneously with the aim of examining the research in depth . The participants in this research were documents and seven experts. The seven experts had the qualification of: 2 experts holding doctor degree in sports evaluation, and 5 experts holding national-certified karate masters with bachelor degree. There were 3 steps in this research. The first step was qualitative analysis of documents, text books and journals of relevant research results to develop the construction of karate agility test for kumite category. The second step was quantitative analysis using the Delphi technique, which was done by asking the experts to assess the construction of karate agility test for kumite category which have been produced during the first stage. The third step was analyzing the results of expert judgment using Aiken formula to test the content validity of the karate agility test for kumite category. The data were collected using questionnaires to be assessed by the rater using a 
rating scale of 4 . The Aiken formula is as follows:

$$
\begin{aligned}
& \mathrm{V}=\sum \mathrm{s} /[\mathrm{n}(\mathrm{C}-1)] \\
& \mathrm{S}=\mathrm{r}-\text { lo } \\
& \text { Lo = lowest value } \\
& \mathrm{C}=\text { highest value }
\end{aligned}
$$

$\mathrm{R}=$ numbers given by the rater

\section{Result}

The results of the document analysis found the definition of the karate agility for the kumite category. The agility in kumite is the speed of footsteps and shifting directions after launching the gyakutsuki punch. In addition, the construction of the kumite category karate agility test is as shown in Figure 1 as follows:

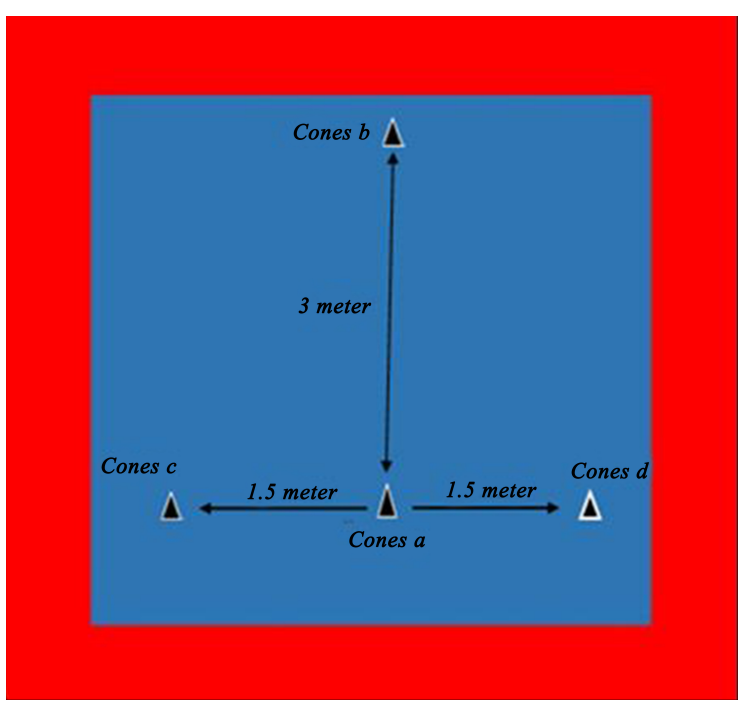

Figure 1. Construction of agility tests a. Distance between cone A and cone B is 3 meters

b. Distance between cone $\mathrm{A}$ and cone $\mathrm{C}$ is 1.5 meters

c. Distance between cone A and cone D is 1.5 meters

\section{The equipment used for the tests are as follows:}

a. The place used is a $6 \times 6$ meters karate mattress

b. 4 cones

c. 1 whistle

d. 1 stopwatch

\section{Number of Testers}

a. One person to give instructions

b. One person to hold the stopwatch

c. One person to record results

\section{Test Procedures}

a. The test's starting point was at the starting line at cone A while hearing the whistle

b. One tester had a whistle. He then turned on the stop watch along with the whistle-blow. The tester moved sideways towards cone $\mathrm{B}$ and held that cone.

c. After holding cone B, the tester performed gyakutsuki punch quickly. After that, he moved sideways to cone A and held that cone. After holding cone A, the tester performed gyakutsuki punch quickly. Then, he move quickly to the left towards cone C.

d. After holding cone C, the tester performed gyakutsuki punch quickly. Then, he move quickly to the right towards cone D. After holding cone D, the tester performed gyakutsuki punch quickly

e. After that, the tester ran towards cone A then held cone A and stop the stopwatch at the same time.

f. The score recorded was the fastest time of two repetitions. This test was done twice with 6 minutes of break.

\begin{tabular}{|c|c|c|c|c|c|c|c|c|c|c|c|c|}
\hline \multirow[t]{2}{*}{ Jury } & \multicolumn{2}{|c|}{ Item 1} & \multicolumn{2}{|c|}{ Item 2} & \multicolumn{2}{|c|}{ Item 3} & \multicolumn{2}{|c|}{ Item 4} & \multicolumn{2}{|c|}{ Item 5} & \multicolumn{2}{|c|}{ Item 6} \\
\hline & Score & $\mathrm{S}$ & Score & $\mathrm{S}$ & Score & $\mathrm{S}$ & Score & $\mathrm{S}$ & Score & $\mathrm{S}$ & Score & $\mathrm{S}$ \\
\hline A & 4 & 3 & 4 & 3 & 4 & 3 & 4 & 3 & 4 & 3 & 4 & 3 \\
\hline B & 4 & 3 & 4 & 3 & 4 & 3 & 3 & 2 & 4 & 3 & 4 & 3 \\
\hline C & 4 & 3 & 4 & 3 & 4 & 3 & 3 & 2 & 4 & 3 & 4 & 3 \\
\hline D & 4 & 3 & 4 & 3 & 4 & 3 & 4 & 3 & 4 & 3 & 4 & 3 \\
\hline $\mathbf{E}$ & 3 & 2 & 4 & 3 & 4 & 3 & 4 & 3 & 4 & 3 & 3 & 2 \\
\hline $\mathbf{F}$ & 2 & 1 & 3 & 2 & 3 & 2 & 4 & 3 & 3 & 2 & 3 & 2 \\
\hline G & 4 & 3 & 4 & 3 & 3 & 2 & 4 & 3 & 3 & 2 & 4 & 3 \\
\hline$\sum \mathbf{S}$ & \multicolumn{2}{|c|}{18} & \multicolumn{2}{|c|}{20} & \multicolumn{2}{|c|}{19} & \multicolumn{2}{|c|}{19} & \multicolumn{2}{|c|}{19} & \multicolumn{2}{|c|}{19} \\
\hline $\mathbf{V}$ & \multicolumn{2}{|c|}{0.85} & \multicolumn{2}{|c|}{0.95} & \multicolumn{2}{|c|}{0.90} & \multicolumn{2}{|c|}{0.90} & \multicolumn{2}{|c|}{0.90} & \multicolumn{2}{|c|}{0.90} \\
\hline
\end{tabular}

\section{Field size for the test}

The Result of Content Validation Test with Aiken Formula

Based on Aiken's calculation analysis, the V values are obtained as shown in the following table 1. 
Based on table 1, item one or the conformity of the test material with the karate category of kumite had a coefficient value of $\mathrm{V} 0.85$; item two or the conformity of the distance between cones had a coefficient value of $\mathrm{V}$ 0.95; item three or the safety of the equipment used had coefficient value of $\mathrm{V} 0.90$; item four or the numbers of repetition had a coefficient value of $\mathrm{V} 0.90$; item five, the clarity of the instrument procedure had a coefficient value of V 0.90; and item six or the test score clarity had a coefficient value of $\mathrm{V} 0.90$. Hendryadi mentioned that if the Aiken value ranges from V0.41 to 0.60 , it is said to have moderate agreement result. If the Aiken value was $\mathrm{V}$ 0.81 to 1.00 , it was said that the raters strongly agreed to each other's opinion. Based on this opinion, it can be said that the karate agility test in the kumite category had high validity. In other words, all the experts highly agree.

\section{Discussion}

Physical is one of the most important things for karate athletes to achieve maximum performance. An athlete is an individual who is demanded to have excellent physical condition in order to win in competitions . The success of an athlete in winning a competition does not come from innate talent. Athletes train hard with the right formula and it takes 10 years of intensive training to be superior in any competition. Karate has two categories (kata and kumite), in which both of them have different characteristics. The kumite in karate is characterized by quick attacks that involve great strategies and tactics. Since kata and kumite matches have different competition conditions, a karate coach must apply different approach in training and assessment activities to optimize the result of competitions. Kata athletes usually prioritize the physical strength and power. Meanwhile in kumite, the athletes usually put forward physical agility because it is a combination of several biomotor components. If the kumite athletes have great physical agility, they will be likely to perform better in a match and can defend and attack more optimally.

Agility is very essential in karate, especially in kumite category, because all the movements made during the match require physical agility. Kumite athletes who have sufficient agility will find it easier to move, avoid opponents' attack, and counterattack quickly and accurately. For that reason, kumite athletes need to be able to measure how good their physical agility is. The agility can be improved through structured and programmed training. In addition, the agility improvement should be observed and measured. By far, there has not been any agility test for kumite category which resembled the movement patterns in a real kumite match. Therefore, karate, especially the kumite category, needs to have specific test to determine the athletes' performance improvement. The authors rarely found suitable agility test for karate, especially kumite, that resembled the movement patterns, techniques, and tactics performed in a real match.
However, the authors found some researches on taekwondo agility test that resembled the real taekwondo match. However, that test was only specialized for taekwondo elite athletes and it obviously could only be used to measure the agility in taekwondo. For that reason, the authors wanted to develop a construction for karate agility test for the kumite category that resembled the movement patterns in a real kumite match in order to observe the kumite athletes' agility improvement when moving forward, sideways, and backward quickly. In addition, this test is also expected to make it easier for coaches to assess the ability of their athletes.

In addition, this research has defined the kumite agility as the ability to step sideways, forward, and change directions quickly after performing gyakutsuki punch. Agility has generally been defined as a person's ability to change direction quickly and accurately . This definition corresponds to the general definition of agility. However, the agility kumite in karate only uses step with punching techniques. Agility is one of the keys to winning in most sport competitions . Some literature explained that agility is the most important aspect of sports in general . Athletes' agility can be described as a combination of movement speed from body control, rapid change of direction, and acceleration while maintaining control of the body when moving forward, sideways and backward as a reflex to a stimulus. . Adequate agility is needed in sports such as football, basketball and hockey. It is also extremely needed in martial arts like taekwondo, judo, and karate because with great agility, the athletes can perform more difficult movements or advanced technical skills associated with rapid leg movement more easily. Agility is the motor ability of the body to make movements in various directions quickly and accurately in sports such as rugby, football, tennis and others. Some literature explained that the types of training running sideways, zigzags and running back and forth were the concepts of agility training types in general . Actually, the agility has simple explanation. Since long time ago, agility was defined as the ability to change direction or speed quickly and precisely . In practice, agility has the same initial and ending body position for changing direction and stop suddenly. Agility is a component that plays an important role in sports because it includes all fast, effective, and efficient body movements . The ability of an athlete to change direction quickly and stop suddenly is a fundamental parameter for high performance sports such as football, basketball, rugby, etc. Some literature explains that game sports (such as football, basketball, hockey, rugby) and martial arts have different agility characteristics. Agility is not only a matter of changing direction quickly, but it also concerns with the ability to maintain and control body position in a balanced manner by changing direction with a series of movements. Good agility will lead to increased balance and reaction time. Therefore, the training program for adolescent athletes should be designed to prioritize multilateral training with coordinating movement of the legs and hands 
in order to prepare the athlete so he has the perfect range of motion in the future. Physical agility training is useful for improving posture stability and balance. Meanwhile, integrative agility training will improve cognitive functions such as perception, mental and working memory to be smarter.

It was found in the construction of the kumite category karate agility test: item one, the content or material got a V value of 0.85 ; item two, the distance between the cone had a $\mathrm{V}$ value of 0.95 ; item three, the safety of the equipment used had a V value of 0.90 ; item four, the number of test replications had a $\mathrm{V}$ value of 0.90 ; item five, the clarity of the test procedure had a $\mathrm{V}$ value of 0.90 ; items six, the clarity of the test score had a $\mathrm{V}$ value of 0.90 .

The above discussion resulted in the content validation for karate agility test in kumite category. The coefficient value was more than 0.78 and the test instrument was considered good. Then, the coefficient values between 0.41 and 0.60 can be said to have moderate agreement results, and the coefficient values between 0.81 and 1.00 can be said to have high agreement results . Based on this opinion, it can be said that the karate agility test in the kumite category had high validity. In other words, all experts had an almost perfect agreement.

\section{Conclusions}

The discussion concluded that the construction of karate agility test for the kumite category has high validity. With the documents of test instruments for the construction of karate agility test for the kumite category, the test have high content validity so it can help ensure the construct validity and giving trust to the reader and researcher regarding this instrument.

\section{Acknowledgements}

The author would like to thank Yogyakarta State University and the Yogyakarta karate association administrators for giving the support and opportunity to collect data for completing this article.

\section{REFERENCES}

[1] Kovacikova. Z. \& Zemková. E, "“The Effect of Agility Training Performed in the Form of Competitive Exercising on Agility Performance," Research Quarterly for Exercise and Sport, no. 1-8, 2020.

[2] Szabo. D. A. Neagu, N. \& Sopa. I. S.,, "Research regarding the development and evaluation of agility (balance, coordination and speed) in children aged 9-10 years," Palestrica of the Third Millennium Civilization \& Sport, vol. 21, no. 33-40, p. 1, 2020.
[3] Zemková. E, "Differential contribution of reaction time and movement velocity to the agility performance reflects sport-specific demands," Human movement, vol. 17, no. 94-101, p. 2, 2016.

[4] Saini. S, "An Assessment of Agility between Judokas and Grapplers: A Comparative Study," International Educational E-Journal Quarterly, vol. 4, no. 2277-2456, p. 3, 2015.

[5] Hojka. V. Stastny. P. Rehak. T. Gołas. A. Mostowik. A. Zawart. M. \& Musálek. M, "A systematic review of the main factors that determine agility in sport using structural equation modeling," Journal of Human Kinetics, vol. 52, no. 115-123,, p. 1, 2016.

[6] Lloyd. R. S. Read. P. Oliver. J. L. Meyers. R. W. Nimphius. S. \& Jeffreys. I, "Considerations for the development of agility during childhood and adolescence," Strength \& conditioning, Vols. 35, no. 2-11, p. 3, 2013.

[7] Arazi. H. Hosseinzadeh. Z. \& Izadi. M, "Relationship between anthropometric, physiological and physical characteristics with success of female taekwondo athletes," Turk. J. Sport Exerc, vol. 18, no. 69-75, p. 2, 2016.

[8] Polat. S. C. Cetin. E. Yarim. I. Bulgay. C. \& Cicioglu. H. I, "Effect of ballistic warm-up on isokinetic strength, balance, agility, flexibility and speed in elite freestyle wrestlers," Sport Mont, vol. 16, no. 85-89, p. 3, 2018.

[9] Bridge. C. A. da. Silva. Santos. J. F. Chaabene. H. Pieter. W. \& Franchini. E, "Physical and physiological profiles of taekwondo athletes," Sports Medicine, vol. 44, no. 713-733, p. 6, 2014.

[10] Roh. H. T. Cho. S. Y. \& So. W. Y , "Taekwondo training improves mood and sociability in children from multicultural families in South Korea: A randomized controlled pilot study," International journal of environmental research and public health, vol. 15, no. 757, p. 4, 2018.

[11] Tabben, M. Chaouachi. A. Mahfoudhi, M. Aloui. A. Habacha. H. Tourny. C. \& Franchini. E,, "Physical and physiological characteristics of high-level combat sport athletes," Journal of combat sports and martial arts, vol. 5, no. 1-5, p. 1, 2014.

[12] Sant'Ana. J. Franchini. E. Murias. J. M. \& Diefenthaeler. F, "Validity of a taekwondo-specific test to measure VO2peak and the heart rate deflection point," The Journal of Strength \& Conditioning Research, vol. 33, no. 2523-2529, p. 9, 2019.

[13] Güler. M. \& Ramazanoglu. N, "Evaluation of Physiological Performance Parameters of Elite Karate-Kumite Athletes by the Simulated Karate Performance Test," Universal Journal of Educational Research, vol. 6, no. 2238-2243, p. 10, 2018.

[14] Peters. M, "Karate-Talk in a Canadian Dojo," Journal for Undergraduate Ethnography, vol. 10, no. 20-34, p. 1, 2020.

[15] Piepiora. P. Szmajke. A. Migasiewicz. J. \& Witkowski. K, "The karate culture and aggressiveness in kumite competitors," do Movement for Culture. Journal of Martial Arts Anthropology, vol. 16, no. 41-47, p. 2, 2016.

[16] Koropanovski. N. Berjan. B. Bozic. P. Pazin. N. Sanader. A. Jovanovic. S. \& Jaric. S, "Anthropometric and physical 
performance profiles of elite karate kumite and kata competitors," Journal of human kinetics, vol. 30, no. 107-114, 2011.

[17] Piepiora. P. A. Migasiewicz. J. \& Witkowski. K, "The traditional karate training and sports fight systems of kumite”,", Roczniki Naukowe Wyższej Szkoty Wychowania Fizycznego i Turystyki w Bialymstoku, vol. 41, no. 62-67, p. $18,2016$.

[18] Piepiora. P. \& Witkowski. K, "Technical preparation of karate competitor for kumite sports fight," Proceedings in ARSA-Advanced Research in Scientific Areas, p. 1, 2015.

[19] P. Piepiora. J. Maśliński. R. Gumienna. W. Cynarski, "Sport technique as a determinant of athletes' personality," Quality in Sport, vol. 6, no. 33-34, p. 1, 2020.

[20] Kim. H. B. Stebbins. C. L. Chai. J. H. \& Song. J. K, "Taekwondo training and fitness in female adolescents," Journal of sports sciences, vol. 29, no. 133-138, p. 2, 2011.

[21] Bonney. E. Aertssen. W. \& Smits-Engelsman. B , "Psychometric properties of field-based anaerobic capacity tests in children with Developmental Coordination Disorder," Disability and Rehabilitation, vol. 41, no. 1803-1814, p. 15, 2019.

[22] Haj-Sassi. R. Dardouri. W. Gharbi. Z. Chaouachi. A. Mansour. H. Rabhi. A. \& Mahfoudhi. M. E, "Reliability and validity of a new repeated agility test as a measure of anaerobic and explosive power," The journal strength \& conditioning, vol. 25, no. 472-480, p. 2, 2011.

[23] Raya. M. A. Gailey. R. S. Gaunaurd. I. A. Jayne. D. M. Campbell. S. M. Gagne. E., ... \& Tucker. C, "Comparison of three agility tests with male service members Edgren side step test, T-test, and Illinois Agility Test," Journal rehabilitation Research \& Development, vol. 50, p. 7, 2013.

[24] Arvidsson. P. Dada. S. Granlund. M. Imms. C. Bornman. J. Elliott. C. \& Huus. K, "Content validity and usefulness of Picture My Participation for measuring participation in children with and without intellectual disability in South Africa and Sweden," Scandinavia Journal of occupation, vol. 27, no. 336-348, p. 5, 2020.

[25] Terwee. C. B. Prinsen. C. A. Chiarotto. A. de Vet. H. Bouter. L. M. Alonso. J. ... \& Mokkink. L. B, "COSMIN methodology for assessing the content validity of PROMsuser manual," Amsterdam: VU University Medical Center, 2018.

[26] Terwee. C. B. Prinsen. C. A. Chiarotto. A. Westerman. M. J. Patrick. D. L. Alonso. J. ... \& Mokkink. L. B, "COSMIN methodology for evaluating the content validity of patient-reported outcome measures: a Delphi study," Quality of Life Research, vol. 27, no. 1159-1170, p. 5, 2018.

[27] JW, Creswell, Reflections on the MMIRA the future of mixed methods task force report, 2016

[28] J. RB, "Mixed methods research design and analysis with validity: A primer," Department of Professional Studies, University of South Alabama, USA, 2014.

[29] Aiken. L.R, "Three coefficients for analyzing the reliability and validity of ratings," Educational and Psychological Measurement, vol. 45, no. 131-142, 1985.

[30] Hendriyadi. H, "Validity Content: Preliminary Development of Questionnaire," Journal of Management Research and Business FE-UNIAT, vol. 2, no. 169-178, p. 2, 2017.

[31] McKinney. J. Velghe. J. Fee. J. Isserow. S. \& Drezner. J. A, "Defining athletes and exercisers," 2018.

[32] van Kooten. G. C. "Re-Considering Long-Term Athlete Development on Coach Education: An Illustration from Judo. 3(1), 83-89.," International Sport Coaching Journal,, vol. 3, no. 83-89, p. 1, 2016.

[33] Shalaby, T. A. R., "The Effect of SAQ Training on the Skill Level of Karate Cadets," Doctoral dissertation, Tanta University Tanta, 2019.

[34] Singh. A. Sathe. A. \& Sandhu. J. S, "Effect of a 6-week agility training program on performance indices of Indian taekwondo player," Saudi Journal of Sports Medicine, vol. 17, no. 139, p. 3, 2017.

[35] Garcia-Gil. M. Torres-Unda. J. Esain. I. Duñabeitia. I. Gil. S M. Gil. J. \& Irazusta, J,, "Anthropometric Parameters, Age, and Agility as Performance Predictors in Elite Female Basketball Players," Journal of Strength and Conditioning Research, vol. 32, no. 1723-1730, p. 6, 2018.

[36] Dietze-Hermosa. M. S. Montalvo, S. Cubillos. N. Gonzalez M. P. \& Dorgo. S, "Association and predictive ability of vertical countermovement jump performance on unilateral agility in recreationally trained individuals," Journal of Physical Education, vo.l 20, no.3, p. 2076 - 2085,2020

[37] Hachana. Y. Chaabène, H. Rajeb. G. B. Khlifa. R Aouadi, R. Chamari. K. \& Gabbett. T. J, "Validity and reliability of new agility test among elite and subelite under 14-soccer players," PLoS One, vol. 9, no. 95773, p. 4, 2014.

[38] Young. W. \& Farrow. D, "The importance of a sport-specific stimulus for training agility," Strength and Conditioning Journal, vol. 35, no. 39-43, p. 2, 2013.

[39] Sekulic. D. Krolo A. Spasic. M. Uljevic. O. Peric. M, "The development of a new stop'n'go reactive agility test," Journal of Strength and Conditioning Research, vol. 28, no. 3306-3312, p. 11, 2014.

[40] Mackala. K. Vodičar. J. Žvan. M. Križaj. J. Stodolka. J. Rauter. S. \& Čoh. M, "Evaluation of the pre-planned and non-planed agility performance: comparison between individual and team sports," International Journal of Environmental Research and public health, vol. 17, no. 975, p. 3, 2020.

[41] de Lima. V. C. Castaño. L. A. A. Boas. V. V. \& Uchida. M. C, "A Training Program Using an Agility Ladder for Community-Dwelling Older Adults," Journal of Visualized Experiments: Jove, no. 157, 2020.

[42] Yuliarto. H. "Content Validity of Creativity Instrument of Playing Football of Sport Social School Students of Real Madrid Yogyakarta State University.," In Proceeding of F International Symposium on The Transition from School to Work, no. 114, 2017. 